\title{
Effect of Tall Building Plan Rectangularity on its Induced Wind Forces
}

\author{
Ahmed A. Mustafa ${ }^{\# 1}$, Mohamed S. A. Saafan ${ }^{* 2}$, Magda M. Elraqabawy ${ }^{\# 3}$ \\ \#1 Graduate student, Structural Department, Faculty of Engineering, Ain Shams University, Cairo, EGYPT \\ ${ }^{* 2}$ Assistant Professor, Structural Department, Faculty of Engineering, Ain Shams University, Cairo, EGYPT \\ ${ }^{\# 3}$ Late Professor, Structural Department, Faculty of Engineering, Ain Shams University, Cairo, EGYPT \\ Corresponding Author: Mohamed S. A. Saafan *2
}

\begin{abstract}
Tall buildings are bluff bodies of medium to high aspect ratio. Wind stagnates at buildings windward façade, reattaches to sides, and finally congregate in the after wake region. Buildings with long along-wind edges give the wind flow the chance to stabilize and move in laminar fashion; however, those with short along-wind edges increase the turbulence of flow pushing air to form vortices after stagnation at windward façade corners and speeding up at leeward façade corners. Building along-wind edges has apparent role in formation of vortex shedding. In order to trace the effect of tall building plan rectangularity, seven building models were studied numerically using FLUENT after validation of the numerical model results with NATHAZ aerodynamic load database (NALD) and real existing building wind tunnel. The models are similar in their crosswind dimension and different in along-wind dimension forming different rectangularity ratios from 0.5 to 2.5 .
\end{abstract}

Keywords-Aerodynamics; Wind loads; Numerical analysis; Computational Fluid Dynamics; Tall buildings.

\section{INTRODUCTION}

Wind loading competes with seismic loading as the dominant environmental loading for structures. It is a fact, all buildings sway during windstorms, but the motion of earlier buildings with heavy full-height partitions has been usually imperceptible and certainly has not been a cause of concern. With the noticed innovation in construction materials and technologies, buildings are going taller and materials are going lighter. (Chen and Zhou 2007 [1], Holmes 2007 [2], and Zhou et al. 1999 [3]).

The term of slender or super high-rise building has appeared pushing engineers and architects to think different to accommodate such a building inside the natural environment without any mutual negative effects. Building must withstand the environmental effects and environment must bear the building footprint. The iconic shape of modern buildings pushes the investigation of their behavior beyond the available standard's applicable limitations. This makes the physical modelling of building as the most proper way for building load and response determination. The physical modelling is not for response investigation only but in some cases, it could be used to decide the building shape in initial conceptual design stage.

The investigation of building behavior under windstorms is complicated due to the wide range of variation of each involved term. Windstorm, building structure, site location and, terrain topography are the main features of such a problem. The flow of wind is complex because its recurrence probability and velocity changes with site location and terrain topography; moreover, many flow situations arise from the interaction of wind with structures

Computational Fluid Dynamics (CFD) is the science of predicting fluid flow, heat and mass transfer, chemical reactions, and related phenomena by solving numerically the set of governing mathematical equations; e.g. conservation of mass, conservation of momentum, conservation of energy, conservation of species, etc. ANSYS CFD simulation software, FLUENT, aims to reduce the total effort and cost required for experimentation and data acquisition. Many researchers considered the CFD simulation, Abdullah et.al 2019 [4], investigated the air flow characteristics along the 2$\mathrm{D}$ profile of a rural house model located on top of a ridge terrain considering the effect of varying the terrain height. Xing et al. 2018 [5], studied the influence of opening position and wind direction on pressure distribution around isolated gable roof buildings with and without openings using CDF and compared with wind tunnel experimental. Tominaga et al. 2015 [6] investigated the air flow around isolated gable-roof buildings with different roof pitches by wind tunnel experiments and CFD.

Studying building envelope shape effect on its induced wind forces is a matter of great importance. It can be traced by monitoring the effect on certain aspects, e.g. building plan rectangularity effect, building cross-sectional shape effect and/or windward or leeward facades configuration effect.

This paper investigates the plan rectangularity aspect. In the course of measuring the effect of rectangularity, this study analyzes seven models with similar crosswind dimension and mean roof height but with different along-wind dimension and thus different rectangularity ratios $(\mathrm{L} / \mathrm{B})$ that ranges from 0.5 to 2.5. The study uses numerical modeling by one of famous CFD codes, FLUENT. Prior to proceed with parametric study, validation of numerical modeling results takes place by comparing its results with the NALD and ASCE7 analytical procedure for an arbitrary building. Also, a real case for actual existing building consists of a 66 office \& residential stories located in Dubai, $250 \mathrm{~m}$ height above ground level. In order to figure the effect of building plan rectangularity, the other building properties should be set to fixed values. Also, the analyzed flow duration and sampled domain size should be the same. 


\section{FLUENT INPUT, OUTPUT AND POST-TEST ANALYSIS}

FLUENT does not offer wind forces in one step but they can be determined by a series of post-test analyses on the program output. The program gives records for the drag \& lift forces coefficients, and base overturning \& torsional moments coefficient fluctuations against time. Then, these results are combined with the real building geometric and dynamic properties on statistical basis of random vibration theory to determine the wind forces [7]. This is thoroughly explained in the following subsections.

\section{A. Fluent Input}

Prior to analyze flow by FLUENT, an important step of domain preparation shall take place. This step includes geometry modeling, a geometry modeler, mesh generator software, GAMBIT, is employed to model the flow domain which is part of atmospheric boundary layer with building and its surroundings immersed in, wall functions assignment, continuum type specification and discretization of domain into finite volumes.

\section{B. Computational Domain, Boundary Conditions \& Grid}

The computational domain defines the region in which the flow field is computed. It first includes the structure for which the wind loads are to be determined. This structure should be represented geometrically as detailed as possible. Additionally, all those buildings or topography that are assumed to influence the structure of interest must be included in the computational domain. The further away these buildings are from the structure of interest the less important is their detailed geometry [8]. Figure 1 presents a scheme of computational domain [9]; however, figure 2 shows a sample dimension of domain used in analysis of steel tall building [10].

\section{Velocity Profile}

Wind velocity varies along the height of boundary layer. This happens due to surface roughness of the earth. Velocity increases as going far from the earth's surface till that roughness effect vanishes and velocity becomes constant. That height at which this happens is the Gradient Height, $\mathrm{Zg}$, in other words it is the thickness of ABL, this is clearly shown in the velocity profiles of inlet, approach, and incident flows in figure 1 . The velocity profile might be determined by power law equation used to determine the mean hourly wind speed from the 3 second gust one [11]:

where:

$$
V_{z}=b(z / 10)^{\alpha} V
$$

$\underline{V}_{\underline{z}}$ : is the mean hourly wind speed in $\mathrm{m} / \mathrm{s}$ at any height $\mathrm{z}, \mathrm{m}$. $b$ and $\alpha$ : are constants based on exposure category.

$V$ : is the 3 -second gust basic wind speed in $\mathrm{m} / \mathrm{s}$.

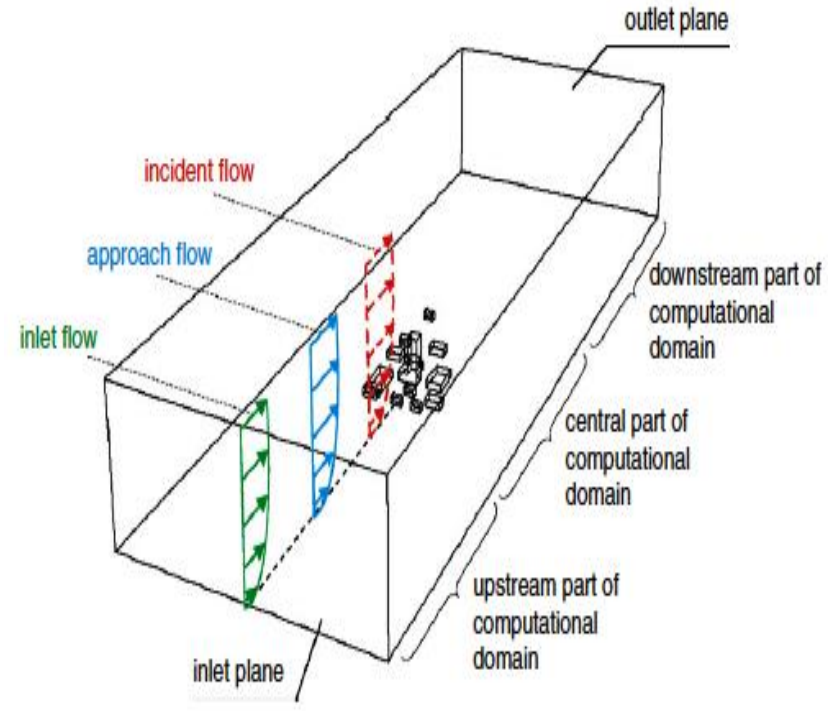

Fig. 1. Computational domain with building models for CFD simulation [9]
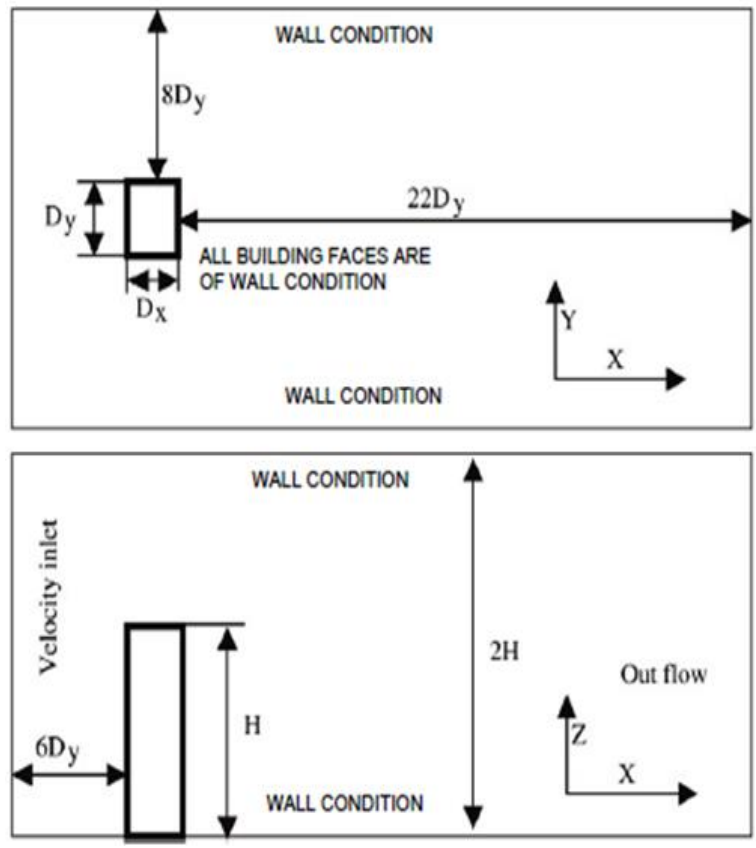

Fig. 2. Computational domain dimensions and wall functions [10]

\section{Fluent Data Output}

FLUENT can give the spectrum of fluctuating base overturning moment with time similar to wind tunnel test measurements, the program can plot/print the Power Spectral Density function (PSD) using Fast Fourier Transform (FFT) built in the program.

\section{E. Output Data Processing}

The PSD function along with Mean $\left(\mathrm{M}^{\bar{\top}}\right)$ and Root Mean Square (RMS) of fluctuating base moment are the target quantities of FLUENT model, here the role of random vibration theory in combination of those quantities with the real building properties starts. 


\section{F. Post-Test Analysis Theoretical Background}

Wind force consists of three components, Mean, Background, and Resonant. Mean component has a static nature; however, the background and resonant ones are of dynamic nature [12]. Generally, wind force is the summation of static part and dynamic part or in other words the summation of mean component and the square root of sum of squares (SRSS) of background and resonant components, (2) $\&$ (3). Figure 3, [3], introduces an illustrative scheme for wind force components.

$$
F_{X, \max }(Z)=\bar{F}_{X}(Z)+\sqrt{\left[\left(g_{B} \sigma_{B, F_{X}(Z)}\right)^{2}+\left(g_{R} \sigma_{R, F_{X}(Z)}\right)^{2}\right]}
$$

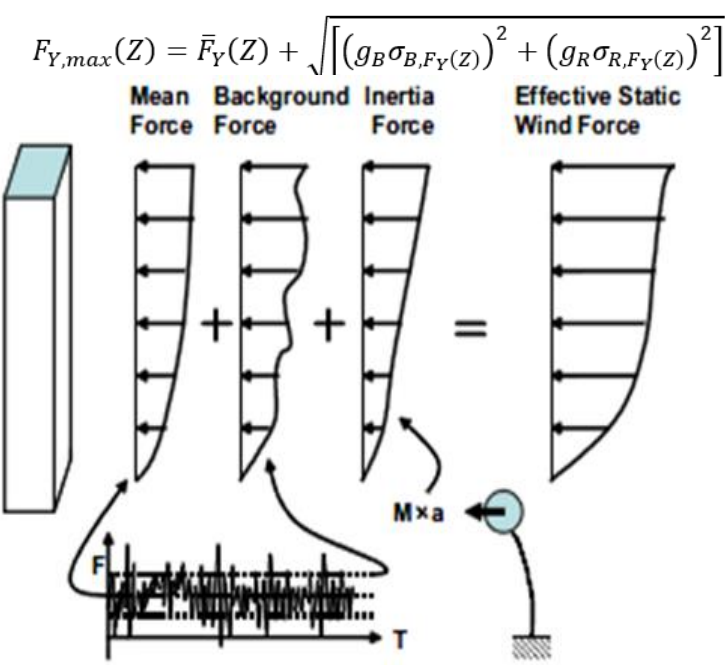

Fig. 3. Components of wind load [3]

The mean component forces, $\left\{\bar{F}_{X}(Z), \bar{F}_{Y}(Z)\right\}$, are the wind force part which pushes the building to sway from its static state, it could be directly determined from mean of fluctuations in the incident flow.

The background component forces makes building oscillate around steady deformed shape, it equals the product of RMS of wind fluctuations,

$\boldsymbol{\sigma}_{B_{3} F_{\boldsymbol{X}}(z),} \boldsymbol{\sigma}_{B_{2} F_{\boldsymbol{V}}(z)}$, and background peak factor $\boldsymbol{g}_{\boldsymbol{B}}$

The inertia component forces are the part of wind force counts for the interaction between wind and structure. it equals the product of the inertia component, $\sigma_{R 1 F_{X}(z),} \sigma_{R 1 F_{v}(z)}$, and resonance peak factor $g_{R}$

\section{NATHAZ AERODYNAMIC LOAD DATABASE}

All commercial wind tunnel facilities have accumulated data of actual buildings test results in their natural surroundings, which together compose an indicative database for future tests. Meanwhile there are some databases involving isolated generic building shapes are available in the literature. A web-based interactive database of aerodynamic loads on several isolated generic building shapes were made accessible for users; NATHAZ Aerodynamic Load Database (NALD), [13].

NALD is a web archived database of aerodynamic loads for a set of isolated building models made of balsa wood and tested in High Frequency Base Balance wind tunnel. The NALD consists of results from 162 different tests, derived from nine cross-sectional shapes, three model heights, two exposure categories and three response directions, [14].

\section{VALIDATION OF NUMERICAL MODELING RESULTS}

An arbitrary tall building with plan dimensions of 40x40 meters and 200 meters height is considered in this validation process. The building is 50 stories with 4.0 meters inter-story height. It is modeled isolated from surroundings. The study considers $300 \mathrm{Kg} / \mathrm{m} 3$ as the building bulk density. The basic wind speed is $38 \mathrm{~m} / \mathrm{s}$ based on 3 -second gust, which equals to mean hourly wind speed of $24.7 \mathrm{~m} / \mathrm{s}$. The site topography is open terrain with scattered obstructions, similar to surface roughness $\mathrm{C}$ of ASCE7; hence, it is of exposure category $\mathrm{C}$. The lateral force resisting system is reinforced concrete shear walls, so that, the fundamental period was found 2.6 seconds based on ASCE7 approximate formula. The damping ratio of the building is $2 \%$.

The arbitrary building is analyzed in FLUENT, Total base overturning moment was calculated and compared with the same from NALD and ASCE7. Table 1 shows a comparison between NALD, FLUENT numerical modeling, and ASCE7.

TABLE I. BASE OVERTURNING MOMENTS FROM NALD, FLUENT AND ASCE7

\begin{tabular}{|l|l|c|c|}
\hline Method & NALD & FLUENT & ASCE7 \\
\hline $\begin{array}{l}\text { Base overturning moment } \\
\text { (kN.m) }\end{array}$ & $1,278,500$ & $1,216,307$ & $1,205,700$ \\
\hline Percentage of difference & $-\cdots--$ & $4.9 \%$ & $5.7 \%$ \\
\hline
\end{tabular}

The total base overturning moment from numerical modeling comes very close to that of NALD with a percentage of difference of $4.9 \%$. The simple shape of the case study building, and small slenderness ratio enabled the analytical procedure of ASCE7 to compete the results of NALD and numerical modeling; also, it acts as another validation tool for the numerical modeling results. The percentage of difference is quite small which could vanish when comparison takes place between various numerical models done on the same basis.

\section{CASE STUDY: MODELING OF A REAL BUILDING VERSUS WIND TUNNEL RESULTS}

It was important to validate the numerical modeling results with wind tunnel test results. A real building with available wind tunnel test results is modeled in GAMBIT and analyzed by FLUENT.

The building is a 66 office \& residential stories building located in Dubai, UAE. It is $250 \mathrm{~m}$ height above ground level, with plan dimensions of $30 \times 35 \mathrm{~m}$ at ground level. The fundamental frequencies and building bulk density are determined by analytical modeling. The 3 -second gust wind speed at site location is $36.4 \mathrm{~m} / \mathrm{s}$, which equals to $23.5 \mathrm{~m} / \mathrm{s}$ mean hourly. The site topography is open terrain with scattered obstructions, similar to surface roughness $\mathrm{C}$ of ASCE7; hence, it is of exposure category C. The building was tested in Boundary Layer Wind Tunnel (BLWT) by high frequency force balance technique to determine the forces on the Main Wind Force Resisting System (MWFRS). Another pressure test has been carried out also to get wind pressures on cladding for façade design. Table 2 introduces the building data from wind tunnel report [15]. Figure 4 shows the building 
plan with considered wind direction, Computational domain size and boundary conditions.

TABLE II

\begin{tabular}{|l|c|}
\hline \multicolumn{2}{|c|}{ BUILDING DATA FROM WIND TUNNEL REP } \\
\hline Frequency in X-dir. & $0.228 \mathrm{HZ}$ \\
\hline Frequency in Y-dir. & $0.204 \mathrm{HZ}$ \\
\hline Bulk density & $420 \mathrm{Kg} / \mathrm{m}^{3}$ \\
\hline 3-second gust basic wind speed & $36.4 \mathrm{~m} / \mathrm{sec}$ \\
\hline Damping ratio & 0.02 \\
\hline Exposure category & $\mathrm{C}$ \\
\hline
\end{tabular}
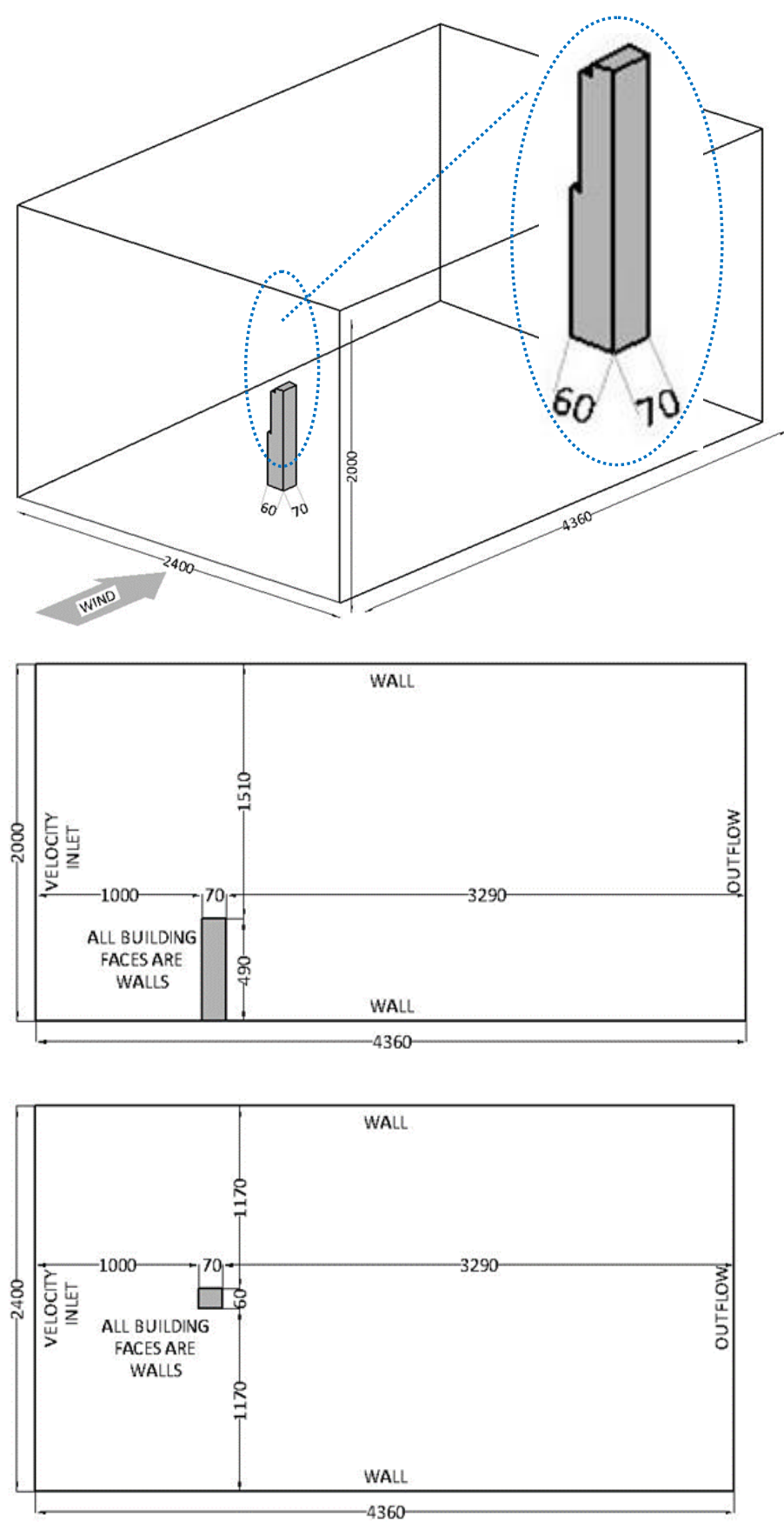

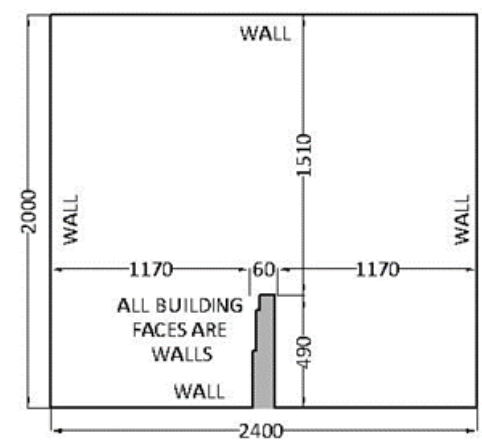

Fig. 4. Computational domain size and boundary conditions $B=30 \mathrm{~m}$, dimensions are in millimeter, model scale is 1:500

The real building is analyzed in FLUENT; 600 seconds of flow records were sampled for analysis. The mean, root mean square and power spectral density function for the model were combined with the real size building properties by random vibration theory. The FLUENT wind velocity contours, plan and elevation, around the building along $\mathrm{X}$-direction that corresponds to across wind dimension of $30 \mathrm{~m}$ are presented in figures 5 and 6 respectively. The plot of the overturning moment is shown in figure 7 . Total base overturning moment was calculated and compared with the same from wind tunnel test forces and ASCE7, table 3 presents such values with percentage of difference.

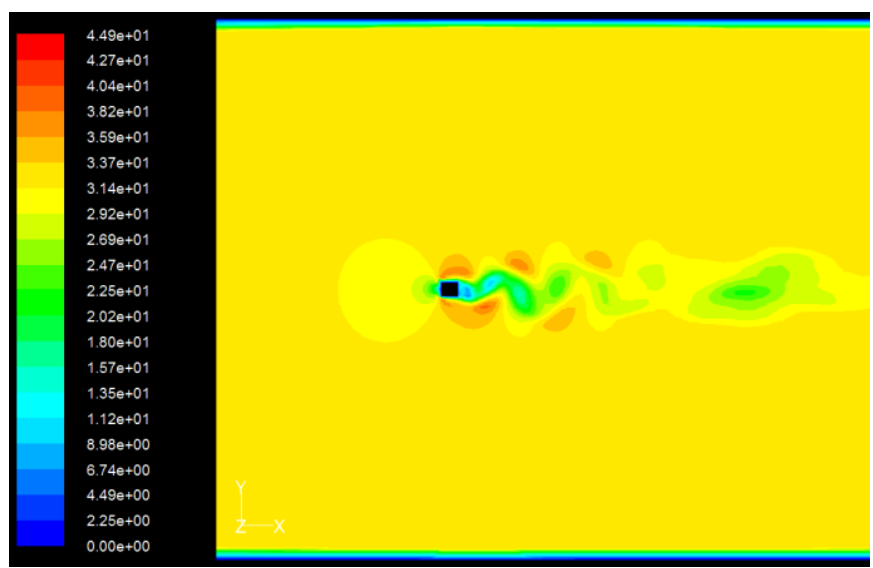

Fig. 5. Case study: FLUENT wind velocity contours, plan

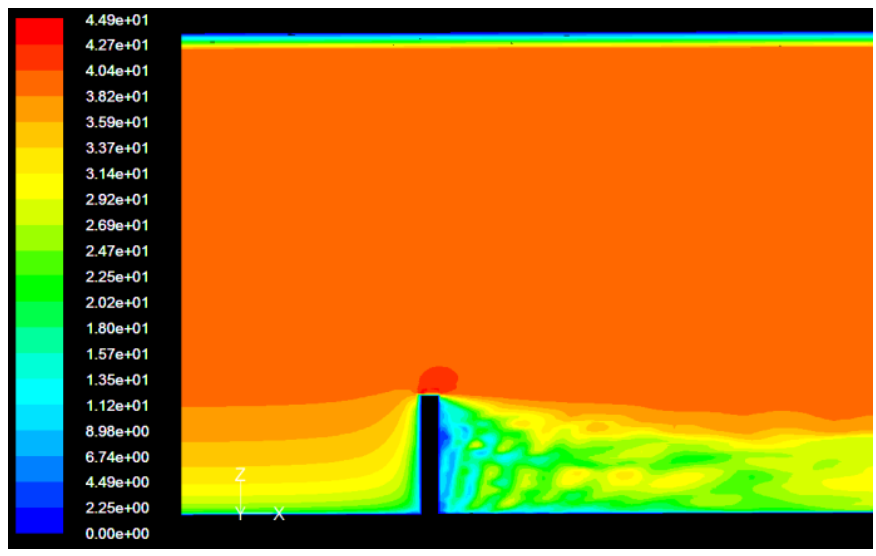

Fig. 6. Case study: FLUENT wind velocity contours, elevation 


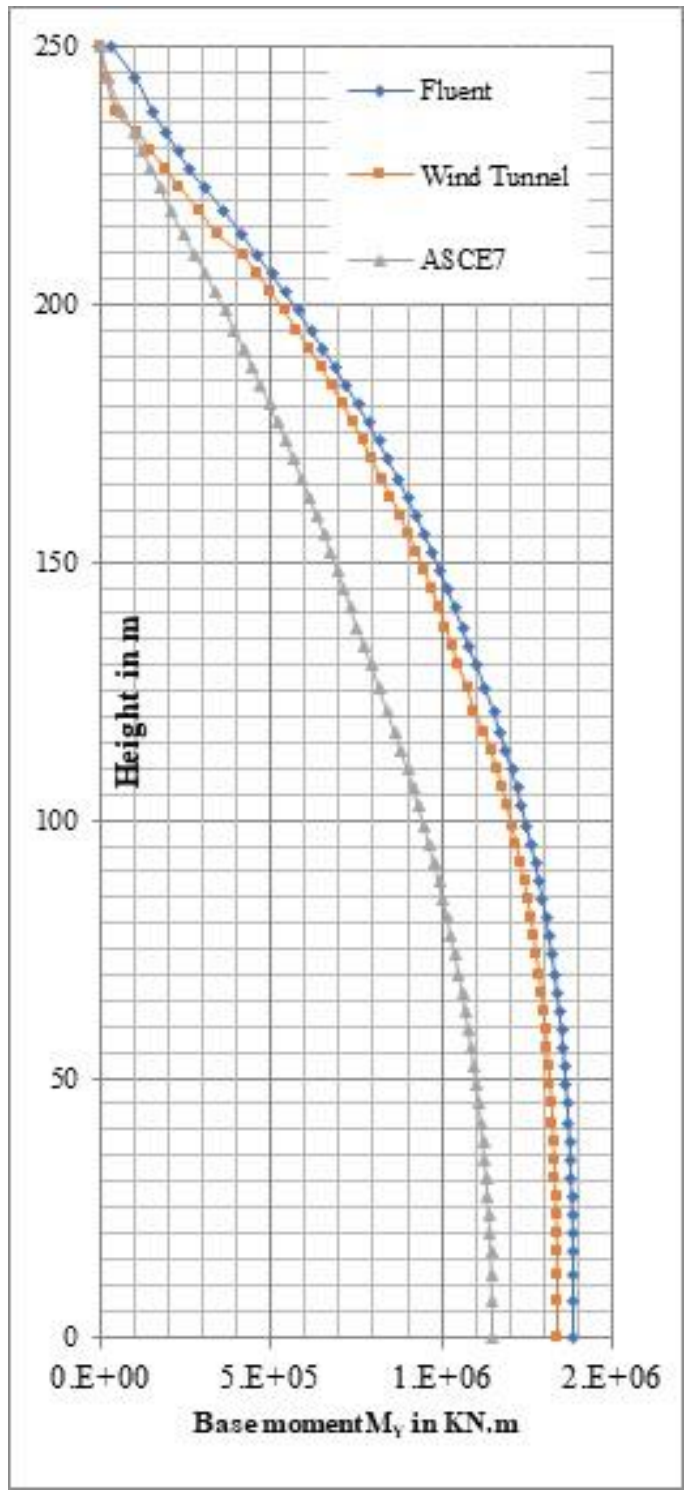

Fig. 7. Case study: overturning moment

TABLE III. CASE STUDY: BASE OVERTURNING MOMENTS FROM WIND TUNNEL, FLUENT AND ASCE7

\begin{tabular}{|l|c|c|c|}
\hline Method & $\begin{array}{c}\text { Wind } \\
\text { Tunnel }\end{array}$ & FLUENT & ASCE7 \\
\hline $\begin{array}{l}\text { Base overturning moment } \\
\text { (kN.m) }\end{array}$ & $1,341,215$ & $1,386,242$ & $1,150,368$ \\
\hline Percentage of difference & $-\ldots--$ & $3.4 \%$ & $14.2 \%$ \\
\hline
\end{tabular}

The percentage of difference came very less, FLUENT numerical model results validation with wind tunnel results was very promising. This cannot guarantee full conformance of both techniques but at least encourages further consideration in assessment of building response under wind loads or parametric comparative studies between different building shapes.

\section{PARAMETRIC STUDY}

Monitoring the effect of building envelope shape is a quite complex job. In order to put it in shape of measurable values a reasonable analogy is needed. one of the major aspects to monitor the relation between building shape and wind forces is the rectangularity of building plan. In the course of measuring the effect of rectangularity, this parametric study uses seven models with similar crosswind dimension and mean roof height but with different along wind dimension and thus different rectangularity ratios $(\mathrm{L} / \mathrm{B})$ that ranges from 0.5 to 2.5 . Table 4 presents the different models in the study, their designation, dimension, and shape.

TABLE IV. STUDY MODELS DESIGNATION, SHAPE AND DIMENSIONS

\begin{tabular}{|c|c|c|c|c|c|}
\hline \\
\hline S.N. & Design & Shape & B & $\mathbf{L}$ & $\mathbf{H}$ \\
\hline 1 & $\mathrm{R}-1: 0.5: 5$ & & 40 & 20 & 200 \\
\hline 2 & R-1:0.625:5 & & 40 & 25 & 200 \\
\hline 3 & R-1:0.75:5 & & 40 & 30 & 200 \\
\hline 4 & $\mathrm{R}-1: 1: 5$ & & 40 & 40 & 200 \\
\hline 5 & R-1:1.5:5 & & 40 & 60 & 200 \\
\hline 6 & $\mathrm{R}-1: 2: 5$ & & 40 & 80 & 200 \\
\hline 7 & $\mathrm{R}-1: 2.5: 5$ & & 40 & 100 & 200 \\
\hline
\end{tabular}

\section{A. Discussion of Results}

The results of the overall wind forces, windward and leeward are shown in figures $(8,9),(10,11)$ and $(12,13)$ respectively. The induced overall wind force of the model with $\mathrm{L} / \mathrm{B}$ ratio equal to 0.5 , compared to the other models with higher L/B ratio, is higher. Assessment of wind forces shared from windward and leeward facades shows that this difference comes from the increase in wind suction on the leeward façade. This result from wind speeds up at windward corners that happen after wind stagnation at windward façade. The wind speed at after wake area is higher and needs the alongwind edge, building side, to stabilize and move again in parallel layers, but as the along-wind dimension gets shorter, it speeds up again at the leeward corners and thus creates high suction zones at the leeward façade. Also, the results could be interpreted based on the bluff body aerodynamics by the behavior of the free shear layers. The flow separates at the windward corners forming a thin region of high shear and vorticity, which is known as a free shear layer that separates the outer flow layers from the building contour. These layers are unstable and eventually form discrete vortices. During the formation of these vortices, air is entrained from the wake region behind the building. As $\mathrm{L} / \mathrm{B}$ increases, the size of the wake region where the air is entrained decreases as the volume of the building occupies part of the wake volume. The suction on the leeward façade proportions with the volume of 
entrained air in the wake region. In conclusion, the buildings of $\mathrm{L} / \mathrm{B}$ ratio less than 0.625 suffer excessive along-wind shear and base overturning moment; while those of L/B ratio equal or higher than 0.625 are almost equal in along-wind story forces with minor differences that appear due to the share of building sides and top

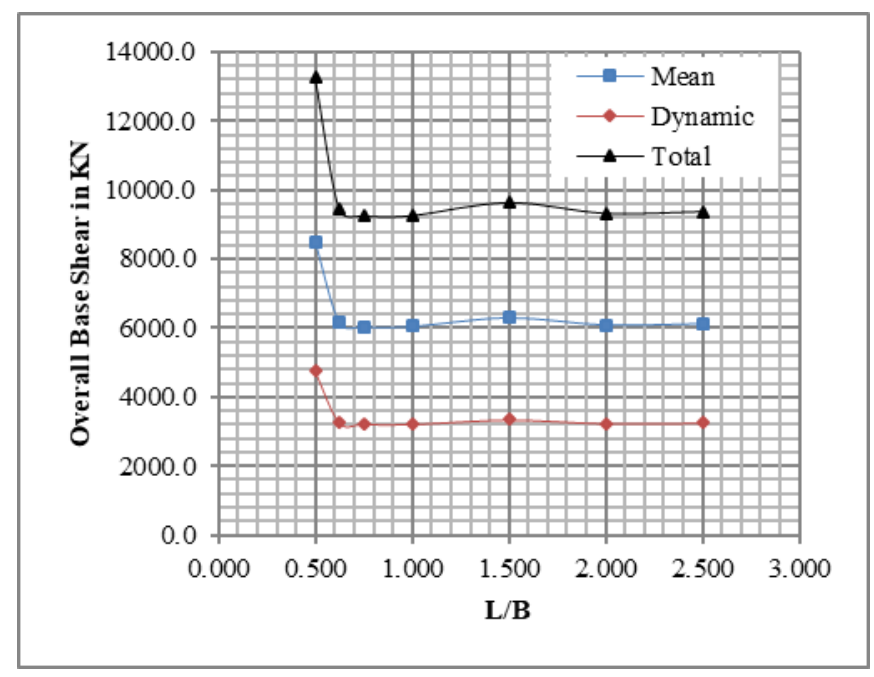

Fig. 8. Overall base shear against $\mathrm{L} / \mathrm{B}$ ratio

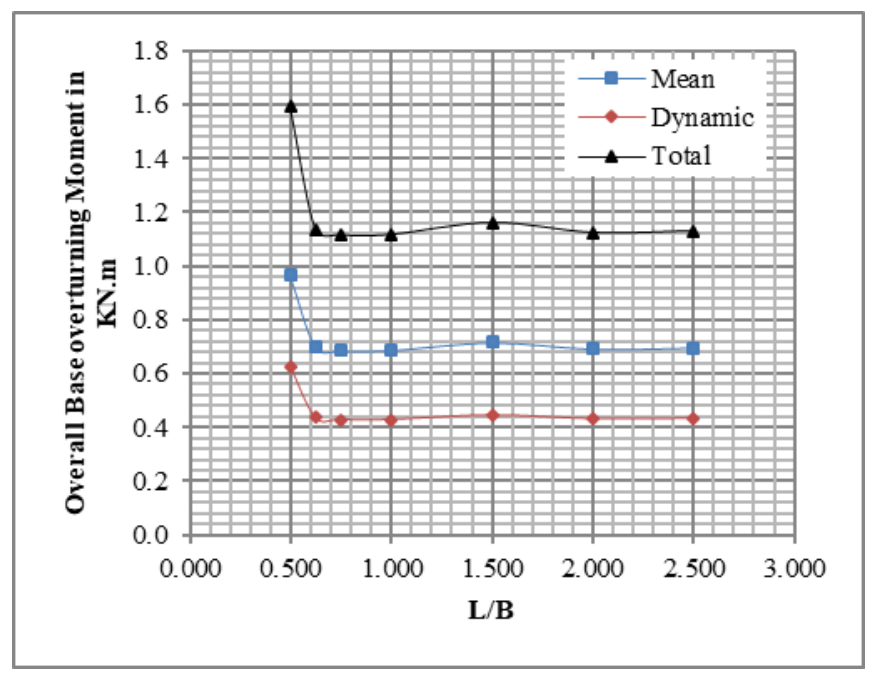

Fig. 9. Overall base overturning moment against $\mathrm{L} / \mathrm{B}$ ratio

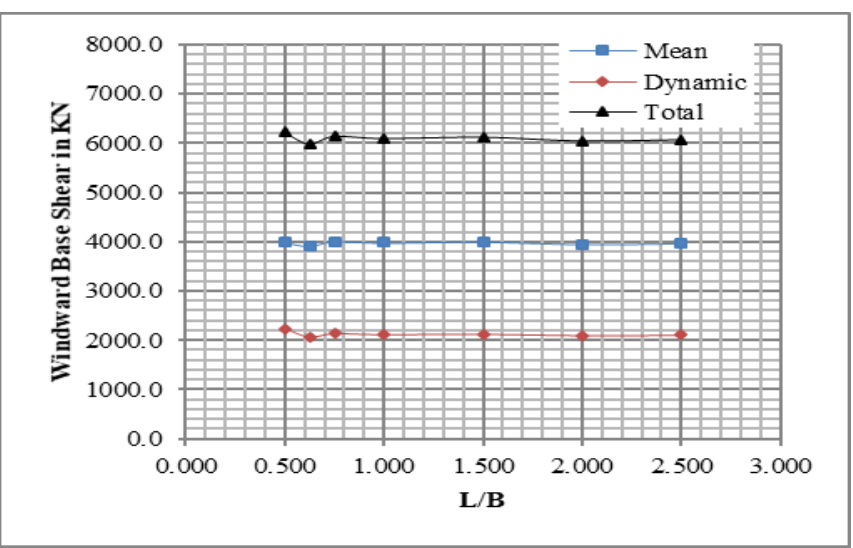

Fig. 10. Windward base shear against $\mathrm{L} / \mathrm{B}$ ratio

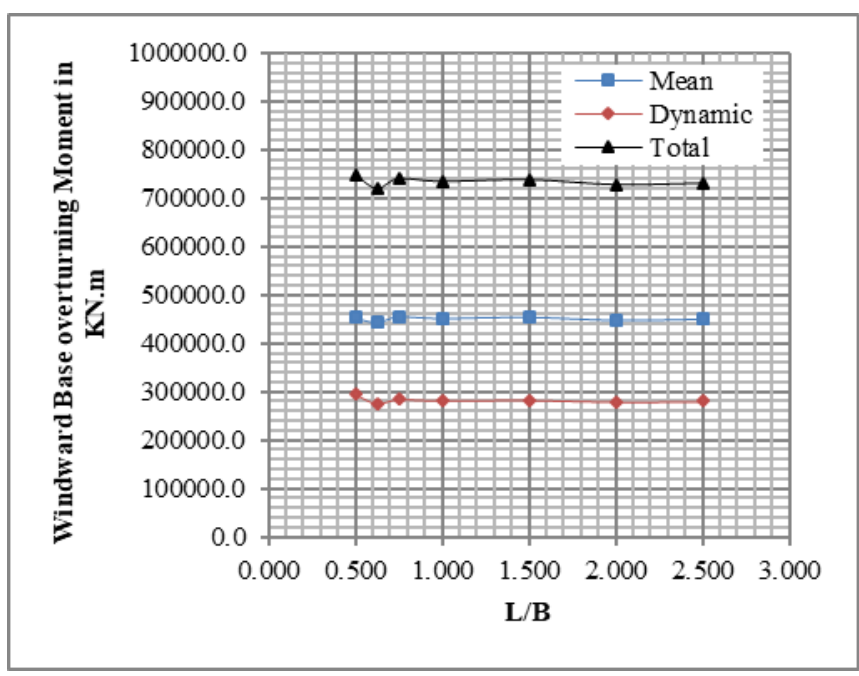

Fig. 11. Windward base overturning moment against $\mathrm{L} / \mathrm{B}$ ratio

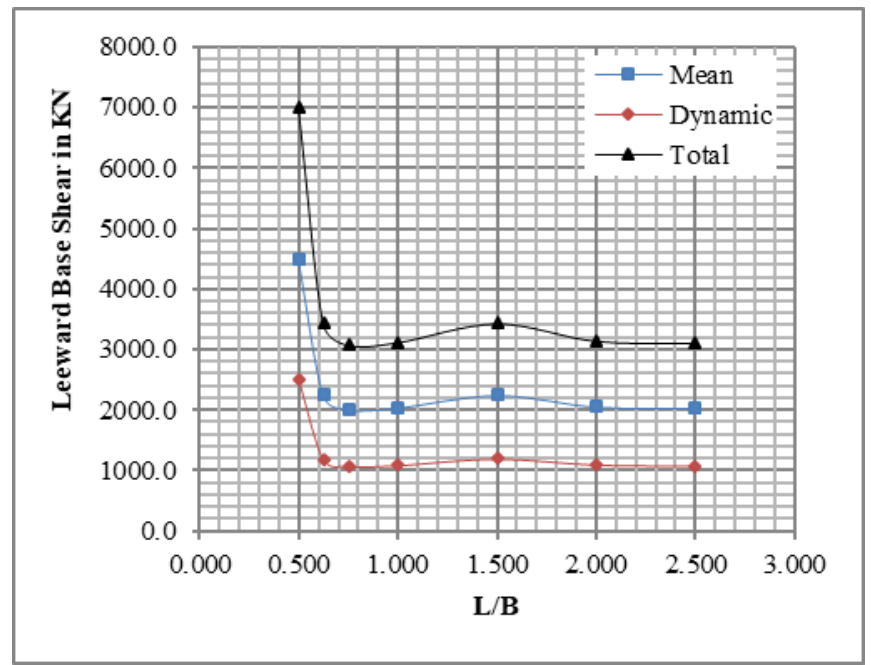

Fig. 12. Leeward base shear against L/B ratio

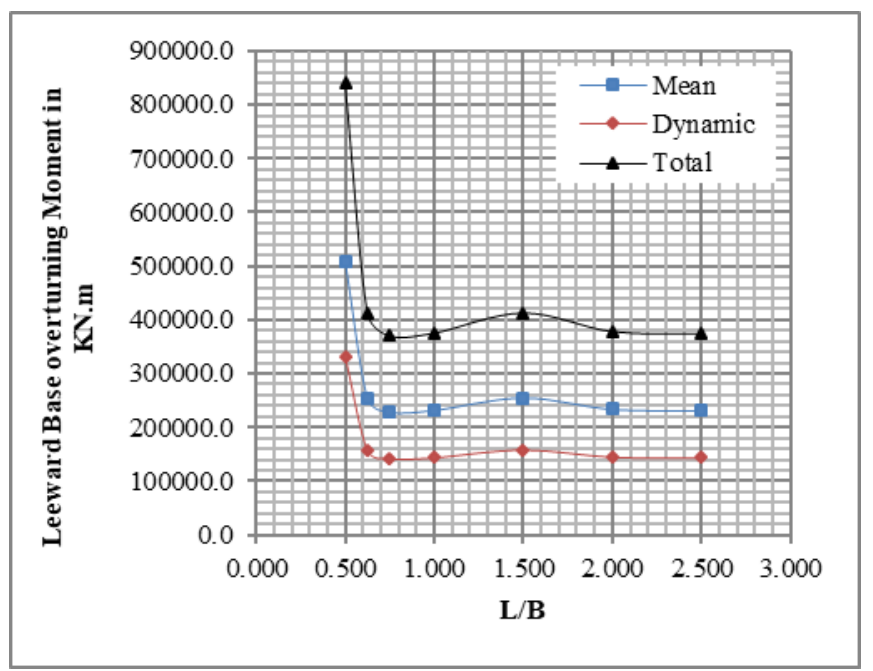

Fig. 13. Leeward base overturning moment against $\mathrm{L} / \mathrm{B}$ ratio 


\section{SUMMARY AND CONCLUSION}

This study presents the use of the ANSYS CFD simulation software, FLUENT, to investigate the effect of rectangularity of tall building numerically as an alternative of wind tunnel tests. FLUENT numerical model of arbitrary building was validated by comparing the base overturning moment results with the NALD and ASCE7 analytical procedure. In addition, real case for actual existing building consists of a 66 office \& residential stories were modeled by FLUENT and compared to wind tunnel test results. Good agreement for base overturning moment in both cases are shown.

The parametric study results show a big difference in the overall wind forces in the range of buildings with L/B less than 0.625. It appears that the leeward façade forces are the responsible of that increase while their windward facades forces receive almost the same wind pressure. The buildings with L/B from 0.625 and higher suffer almost the same overall wind forces as they receive almost equal pressure/suction on their windward and leeward facades.

Although the percentage of difference between FLUENT numerical model and wind tunnel results is promising but this cannot guarantee full conformance of both techniques but at least encourages further consideration in assessment of building shape and response under wind loads.

\section{ACKNOWLEDGMENT}

The authors express their gratitude for the wind tunnel data employed in this research from e.construct, UAE, the designer and value engineering consultant of the study case building adopted herein. The first author is an employee of that engineering consultancy firm.

\section{REFERENCES}

[1] X. Z. Chen, and N. Zhou, "Equivalent static wind loads on low-rise buildings based on full-scale pressure measurements", Eng. Struct., 29(10), 2007, pp.2563-2575

[2] J. D. Holmes, Wind Loading of Structures (second edition), Taylor and Francis Group, London, UK., 2007.

[3] Y. Zhou, A. Kareem, M. Gu., "Gust Loading Factors for Design Applications", Proceedings of the 10th International Conference on Wind Engineering, Copenhagen, 1999.

[4] J. Abdullah, S. S. Zaini, M. S. Abdul Aziz, T. A. Majid, W. N. W. Yahya, S. N. C. Deraman, "CFD prediction of air flow characteristics along the profile of a rural house model located on different ridge terrain height" National Colloquium on Wind \& Earthquake Engineering, IOP Conf. Series: Earth and Environmental Science 244, 2019.

[5] F. Xing, D. Mohotti, K. Chauhan "Experimental and numerical study on mean pressure distributions around an isolated gable roof building with and without openings" Building and Environment, Volume 132, pp. 30-44, March 2018.

[6] Y. Tominaga, S. Akabayashi, T. Kitahara, Y. Arinami, "Air flow around isolated gable-roof buildings with different roof pitches: Wind tunnel experiments and CFD simulations" Building and Environment, Volume 84, pp. 204-213, January 2015

[7] C. Lalanne. "Mechanical Vibration \& Shock, Random VibrationVolume III", 2002.

[8] T. Stathopoulos, C. C. Baniotopolous. "Wind Effects on Buildings and Design of Wind-Sensitive Structures", 2007.

[9] B. Blocken, T.Stathopoulos, J. Carmeliet. "CFD Simulation of The Atmospheric Boundary Layer: Wall Function Problems". Atmospheric Environment 41, pp. 238-252, 2007.

[10] S. Huang, Q. S. Li, S. Xu, "Numerical Evaluation of Wind Effects on a Tall Steel Building". Journal of Constructional Steel Research, 63, pp.612-627, 2007.

[11] American Society of Civil Engineers, "Minimum Design Loads for Buildings and Other Structures". ASCE7, 2010.
[12] D. Y. Kim, J. Y. Kim, M. H. Lee, S. D. Kim. "A Study on the Evaluation Methods of Equivalent Design Wind Loads for Tall Buildings". Council on Tall Buildings and Urban Habitat Journal, pp. 1080-1087, October 2004.

[13] Y. Zhou, T. Kijewski, and A. Kareem. "Aerodynamic Loads on Tall Buildings: Interactive Database". Journal of Structural Engineering, ASCE, pp. 394-404, March 2003.

[14] D. K. Kwon, T. K. Correa, A. Kareem. "e-Analysis of High-Rise Buildings Subjected to Wind Loads". Journal of Structural Engineering, ASCE, pp. 1139-1153, July 2008.

[15] Rowan Williams Davies \& Irwin Inc. (RWDI), "Wind-Induced Structural Responses, Case Study Tower in Dubai, UAE”, March 2006. 